\title{
Alcohol and behavioral variability with fixed-interval reinforcement
}

\author{
LOWELL T. CROW and PATRICK J. HART \\ Western Washington University, Bellingham, Washington
}

\begin{abstract}
Rates of response were noted in rats under a fixed-interval 1-min schedule of reinforcement after repeated ethanol treatments of $0.0,1.0$, or $1.4 \mathrm{~g} / \mathrm{kg}$. Response rates of the initial and concluding segments of the interval were diminished differentially by the high dose, and a measure of response uncertainty on the last treatment day indicated reduced behavioral variability in the high-dose group throughout the session. The results are discussed as they relate to the theory of Devenport and Merriman of the general effects of alcohol upon behavior.
\end{abstract}

Under certain conditions, alcohol is known to diminish behavioral variability. Thus, operant rates of response on continuous-reinforcement schedules were stabilized by ethanol (Crow, McWilliams, \& Ley, 1979), and rats' responding in a radial-arm maze showed less variability in paths chosen and sequence of visitation with alcohol (Devenport \& Merriman, 1983). The latter authors suggest that a great many of the common effects of alcohol upon behavior may be, in fact, a suppression of behavioral variability.

Ethanol has been found to produce rate-dependent effects upon behavior (Leander, McMillan, \& Ellis, 1976), and one of the present authors has related these alcohol effects to decreased behavioral variability (Crow, 1982). The present study was designed to extend these earlier findings to include an independent measure of behavioral variability as well as an estimate of the influence of alcohol tolerance upon the effect.

\section{METHOD}

\section{Subjects}

Twenty-one experimentally naive male albino rats were used. The animals, bred from Sprague-Dawley stock at Western Washington University, ranged in weight from 346 to $446 \mathrm{~g}$ and in age from 239 to 251 days at the start of the experiment.

\footnotetext{
Apparatus

Four Gerbrands water-delivery operant chambers were programmed for a fixed-interval 1-min schedule of reinforcement and to provide running counts of responses within each 30 -sec interval segment.
}

\footnotetext{
Alcohol Doses

Intraperitoneal injections were given in amounts of 1.0 or $1.4 \mathrm{~g} / \mathrm{kg} 10 \mathrm{~min}$ prior to tests. Control injections were isotonic saline. Injection solutions were $95 \%$ ethanol and tap water in a concentration of $23.75 \%(\mathrm{v} / \mathrm{v})$

Procedure

The animals were assigned randomly to one of three groups

The authors' mailing address is: Department of Psychology, Western Washington University, Bellingham, Washington 98225.
}

of seven rats each, adapted to a 23.5 -h water-deprivation schedule, and trained to a stable level of fixed-interval 1-min responding in a 30-min daily session. Test sessions consisted of alternateday injections of control, low $(1.0-\mathrm{g} / \mathrm{kg})$, and high $(1.4-\mathrm{g} / \mathrm{kg})$ group doses of alcohol for 6 days (12 days total). Measures were made of the number of responses in each 30 -sec interval segment on all test days, and on Test Day 6, measures were made of barpressing and approach to the dipper sequences for the entire session.

\section{RESULTS AND DISCUSSION}

Figure 1 shows the response rate (responses per minute) for each segment of each dosage group for each of the 6 test days. These data were subjected to a dosage $\mathrm{x}$ interval segment $\mathrm{x}$ sessions analysis of variance (Type VI). The main "between" effect, dosage, was significant $[\mathrm{F}(2,18)=76.28, \mathrm{p}<.05]$, as was the first "within" effect, intervals $[F(1,18)=287.44, p<.05]$, and the second "within" effect, sessions $[F(5,90)=$ $3.33, \mathrm{p}<.05]$. The dose $\mathrm{x}$ interval interaction was significant $[\mathrm{F}(2,90)=78.88, \mathrm{p}<.05]$, whereas the dose $x$ session interaction was not significant $[F(5,90)=1.22$, $\mathrm{p}>$.05]. The interval $\mathrm{x}$ session $\mathrm{x}$ dose interaction was significant $[F(10,90)=2.60, p<.05]$. Two-group comparisons for the "between" effect revealed mean significant differences between the high dose and the other treatment groups, but no other two-group comparisons were significant.

The data for the uncertainty index (Crow et al., 1979) consisted of sequences of barpressing and approach-to-dipper responses throughout the final test day. Analysis of variance yielded a significant effect $[F(2,18)=4.12, p<.05]$. The high-dose mean was 0.510 , the low-dose mean was 0.706 , and the control mean was 0.769 . Two-group comparisons showed a significant difference between the high-dose group and the other groups, but no other two-group comparisons were significant.

In summary, the results indicate corroboration of earlier findings (Crow, 1982; Leander, McMillan, \& Ellis, 

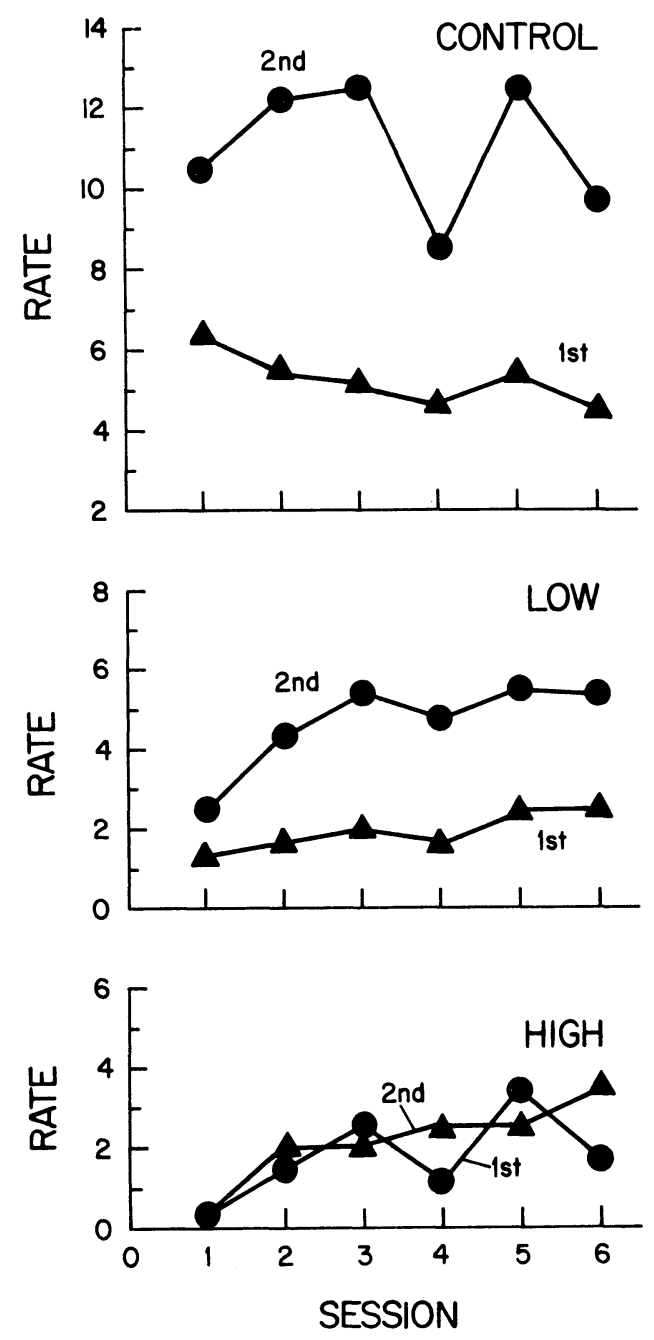

Figure 1. Mean response rate for each test day for the initial (1st) and concluding (2nd) segments of the interval.
1976) of a rate-dependent effect of ethanol on operant responding. The interval $\mathrm{x}$ dose interaction indicates that ethanol affects high rates (concluding segments of the interval) to a greater extent than it does lower rates (initial segments of the interval) in that the former are more depressed (Figure 1). Although species differences may account for the discrepancy, the present findings, as well as those reported earlier (Crow, 1982), do not indicate an increased responding rate as a result of the ethanol in the initial interval segments as found by Leander, McMillan, and Ellis (1976). The latter study did not control for tolerance effects, but the present study does not support the notion that tolerance accounts for the difference, at least that tolerance acquired through 12 treatment days.

In addition, the present results support the supposition that alcohol may produce rate-dependent effects via a suppression of behavioral variability, since the diminished rate of rate change within the fixed interval was correlated with the independent measure of uncertainty.

\section{REFERENCES}

Crow, L. T. Ethanol-induced response stereotypy: Simple alternation, fixed-interval rates of response, and response location. Bulletin of the Psychonomic Society, 1982, 19, 169-172.

Crow, L. T., McWrlliams, L., LEY, M. Relative stereotypy of water-ingestive behavior induced by chronic alcohol injections in the rat. Bulletin of the Psychonomic Society, 1979, 14, 278-280.

Devenport, L. D., \& Merriman, V. J. Ethanol and behavioral variability in the radial-arm maze. Psychopharmacology, 1983, 79, 21-24.

Leander, D. J., McMillan, D. E., \& Ellis, F. W. Ethanol and isopropanol effects on schedule controlled responding. Psychopharmacology, 1976, 47, 157-164.

(Manuscript received for publication August 8, 1983.) 